OPEN ACCESS

Edited by:

Chrystalina A. Antoniades, University of Oxford, United Kingdom

Reviewed by:

Sandro Mussa-Ivaldi, Northwestern University, United States

Tjeerd W. Boonstra University of New South Wales,

Australia

Jean-René Cazalets,

Centre National de la Recherche Scientifique (CNRS), France

*Correspondence: Yury Ivanenko y.ivanenko@hsantalucia.it

Specialty section: This article was submitted to Neuroprosthetics, a section of the journal Frontiers in Neuroscience

Received: 09 August 2017 Accepted: 05 March 2018 Published: 20 March 2018

Citation:

Ivanenko Y and Gurfinkel VS (2018) Human Postural Control. Front. Neurosci. 12:171. doi: 10.3389/fnins.2018.00171

\section{Human Postural Control}

\author{
Yury Ivanenko ${ }^{1 *}$ and Victor S. Gurfinkel ${ }^{2}$ \\ ${ }^{1}$ Laboratory of Neuromotor Physiology, IRCCS Fondazione Santa Lucia, Rome, Italy, ${ }^{2}$ Biomedical Engineering Department, \\ Oregon Health and Science University, Portland, OR, United States
}

From ancient Greece to nowadays, research on posture control was guided and shaped by many concepts. Equilibrium control is often considered part of postural control. However, two different levels have become increasingly apparent in the postural control system, one level sets a distribution of tonic muscle activity ("posture") and the other is assigned to compensate for internal or external perturbations ("equilibrium"). While the two levels are inherently interrelated, both neurophysiological and functional considerations point toward distinct neuromuscular underpinnings. Disturbances of muscle tone may in turn affect movement performance. The unique structure, specialization and properties of skeletal muscles should also be taken into account for understanding important peripheral contributors to postural regulation. Here, we will consider the neuromechanical basis of habitual posture and various concepts that were rather influential in many experimental studies and mathematical models of human posture control.

Keywords: posture control, equilibrium, muscle tone, postural reflexes, multisensory interactions, postural body scheme

\section{INTRODUCTION}

Life evolved in the presence of gravity and it has long been recognized, from ancient Greece to our days, that posture is maintained by tonic muscle contractions acting against gravity and stabilizing the positions of body segments. The Greek physician Galen of Pergamon was, probably, the first to introduce the concept of muscle tone in his work "De motu musculorum" (Galen, 1549). From clinical observations, it has long been known that lesions of the central nervous system may result in pronounced changes in posture. Systematic experimental studies of the physiological mechanisms of postural regulation only began a century ago by Sherrington $(1906,1915)$ and were further developed by Magnus (Magnus and de Klein, 1912; Magnus, 1924) and Rademaker (1931). Various biomechanical and neurophysiological approaches have been used for understanding the mechanisms of balance control (Horak and Macpherson, 1995).

We start this review with an influential scheme of the upright posture control based on the idea of the inverted pendulum and the presence of center of pressure ( $\mathrm{CoP})$ oscillations, as important measure of postural stability. In the simplified inverted pendulum model of the upright human posture, the center of body mass (CoM) is the single controlled variable (Winter et al., 2003). In quiet standing, CoP oscillates either side of CoM to keep it in a fairly constant position between the two feet (Figure 1C). Since the center of body mass (CoM) is located relatively high (in the trunk, $\sim 1 \mathrm{~m}$ above the ankles that determines the length of the inverted pendulum) and the base of support is relatively small, the posture is inherently unstable. Accordingly, one might conclude

Abbreviations: CoM, centre of body mass; $\mathrm{CoP}$, centre of pressure. 
A

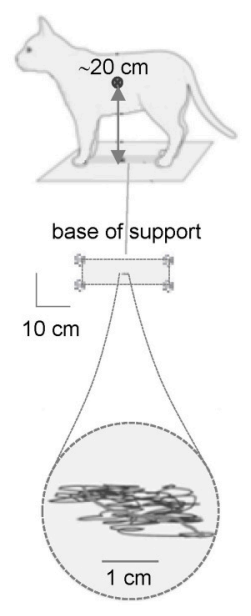

B
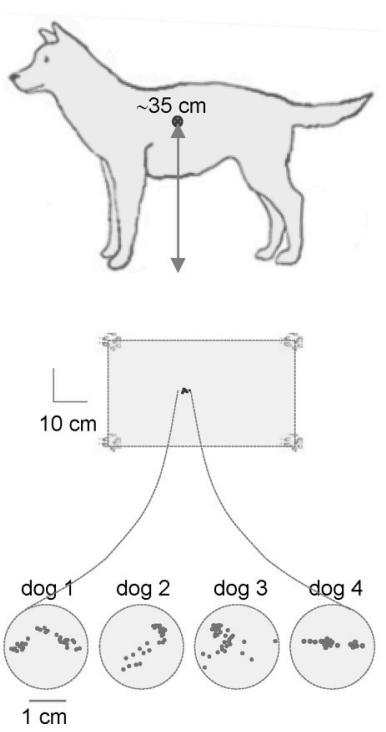
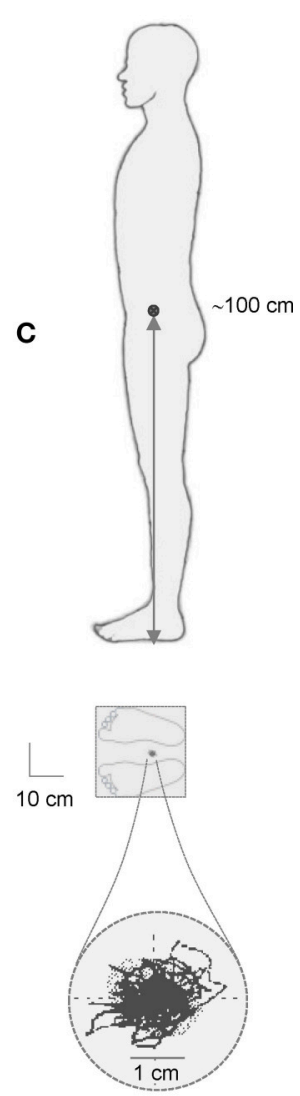

FIGURE 1 | Center of pressure (CoP) fluctuations during quiet standing in the cat (A), dog (B) and human (C). Examples of the CoP traces (lower) are adapted from MacPherson and Horak (2012) with permission in (A), redrawn from Brookhart et al. (1965) in (B) and modified from Ivanenko et al. (1999) in (C). The size of the base of support is schematically depicted in the middle panels. Note comparable CoP oscillations ( $\sim 2 \mathrm{~cm})$ in quadrupeds with regard to human despite the 5 -fold difference in the height of the center of body mass over the support.

that the higher the CoM location, the larger the CoP oscillations. However, this statement is a simplification and appears to be misleading. For instance, Figure 1 illustrates typical examples of the center of pressure fluctuations during quiet standing in the cat, dog and human. Note the similar CoP oscillations $(\sim 1-2 \mathrm{~cm})$ despite substantial differences in the height of the center of body mass over the support. Comparable $(\sim 1 \mathrm{~cm}$ CoP) body sway was also observed in horses (Clayton and Nauwelaerts, 2014) and in rats ( $\sim 2 \mathrm{~cm} \mathrm{CoP})$ trained to stand bipedally (Sato et al., 2015). Therefore, the simple scheme "the lower the CoM, the smaller the CoP oscillations" is deceptive, or at least it cannot be generalized to animals of different size. In addition, the amplitude of CoP oscillations is much smaller than the actual base of support (schematically depicted in Figure 1, middle panels) and would likely provide stability even if it were larger.

Thus, it is important to stress that simple biomechanical considerations can explain the postural behavior only to some extent. Furthermore, the CoP oscillations reflect only an operative level of posture control related to stabilization of specific postural body segments' orientations. However, what are the principles determining habitual postural configurations and tonic muscle activity along the body axis? Postural tone (often associated with antigravity support) represents the tonic activation of muscles in order to provide specific postural attitude and generate force against the ground to keep the limbs extended. The habitual stance vary across animals and may include extended limbs or semiflexed posture. Antigravity support in humans is partly provided by passive bone-onbone forces in joints, stretched ligaments and muscles, but it also requires active contraction in lower limb, trunk, and neck extensors. The control of postural tone is not simple and requires specialized neural circuitry. Detailed information is required about underlying neural circuitry, as well as about underlying cellular processes in generating prolonged muscle force and stiffness. It is worth noting that postural attitude in different individuals is determined by both individual morphology and specific low-level muscle activity, which can be significantly affected also by different pathological conditions. Integration of several sensory and motor areas has developed through millions of years of life evolution with the purpose of providing accurate regulation of body orientation in the gravity field.

Here we review the experimental challenges that affect the way we define and consider the mechanisms of muscle tone and postural regulation. In the first section, we briefly discuss structural and functional complexity of postural muscles because any reflection on muscle tone and its control should consider 
the knowledge of the unique structure and properties of skeletal muscles. In the following sections, we discuss the ideas and approaches that represent or represented important conceptual frameworks for investigating human posture control.

\section{STRUCTURAL AND FUNCTIONAL COMPLEXITY OF POSTURAL SKELETAL MUSCLES}

The structure and function of skeletal muscle allow wide range of activities, from rapid production of forces and movement to long-lasting maintenance of body segment orientation relative to gravity. In addition, task-specific activation of functionally different types of muscle fibers that compose a given muscle can accomplish a rich repertoire of muscle contractions and energetics of force production. Postural tone is commonly viewed as low-level muscle tension observed in both distal and proximal (trunk and neck) skeletal muscles. Nevertheless, one cannot reflect upon postural tone by considering only the neural input from the sub-cortical and cortical structures. Recent biochemical and biomechanical findings have forced a serious re-evaluation of structural and functional muscle complexity (Knight, 2016). In particular, the sliding filament theory for muscle contraction has been expanded to include regulatory and cytoskeletal proteins that are responsible for the viscoelastic properties of muscle and economy of force production - the key peripheral contributions to postural regulation.

The sliding filament theory is based on the model, where actin and myosin filaments slide past each other, and it was introduced in 1954 independently by the two groups (Huxley and Hanson, 1954; Huxley and Niedergerke, 1954). Hugh Huxley formally proposed the mechanism for sliding filament that is called crossbridge model. According to his model, filament sliding occurs by cyclic attachment and detachment of myosin on actin filaments. Contraction occurs when the myosin pulls the actin filament toward the center of the A band, detaches from actin and creates a force (stroke) to bind to the next actin molecule. However, the modern views on the mechanism of muscle contraction include three sliding filaments, namely, actin, myosin and titin (Knight, 2016). It is important to note that, in addition to the links to the sarcolemma via T-tubules and the sarcoplasmic reticulum, sarcomeres are linked by other extra-sarcomeric cytoskeletal structures at the Z-disk and M-band. This structure undergoes reversible axial and transverse conformational changes in the contracting sarcomere. The cytoskeletal sarcomeric structure plays a key role in the sliding filament theory (Gautel and Djinović-Carugo, 2016).

In the context of postural function of skeletal muscles and stabilization of body segments, elastic properties of the skeletal musculature and muscle tension are tightly related to regulatory and cytoskeletal proteins. Even though postural muscular activity is rather small, it is worth stressing that any posture is not passive and specific small activity of neck, trunk and limb muscles determines resting tension, axial tone, individual postural attitudes, facial expression, etc. (Jankovic,
2003; Gurfinkel et al., 2006; Wright et al., 2007; Caneiro et al., 2010). Long-lasting maintenance of postural muscle activity (minutes or even hours) is associated with low energy cost. Postural activity normally engages slow muscle fibers, which are more resistant to fatigue. How to control this machinery during posture and small movements that are often present during posture maintenance? In addition to the selective activation of appropriate muscle fibers, a poorly understood, but intriguing, aspect of postural muscle tone encompasses the mechanisms of muscle elasticity, force enhancement and energy conservation.

For instance, static stiffness relies on calcium-dependent stiffening of the activated fibers, independent of crossbridge formation, and titin appears to have all the characteristics required to account for the static stiffness properties (Colombini et al., 2016). Force enhancement may also result from an interaction between an elastic element in muscle sarcomeres and the cross-bridges, which, in turn, interact with the elastic elements to regulate their length and stiffness. A muscle model based on the winding filament hypothesis can predict residual force augmentation in muscles (Nishikawa, 2016). The giant protein nebulin is one of the important regulatory proteins and was proposed to function as a "molecular ruler" to specify the lengths of the thin filaments, which plays a role in numerous cellular processes including regulation of muscle contraction, viscoelastic properties, Z-disc formation, and myofibril assembly (Chu et al., 2016). Interaction between titin and nebulin is still uncertain. Finally, usedependent changes in muscle fiber composition (Hoppeler, 2016) and progressive decreases in muscle contraction time during child development along with maturation of the central nervous system in the control of posture and movement (Dayanidhi et al., 2013) reflect the functional benefits of such continual maturation and point toward the important role of muscle phenotypic plasticity. The abovementioned topics were traditionally overlooked although the progress in elucidating the molecular mechanisms of muscle contraction opens new avenues in understanding important peripheral contributors to postural regulation and muscle plasticity.

\section{CONCEPTUAL FRAMEWORKS AND APPROACHES FOR INVESTIGATING POSTURAL CONTROL}

Upright bipedal stance is traditionally described to depend on sensory (vision, vestibular, and somatosensory) input to provide postural equilibrium and a proper alignment of body segments with respect to gravity. The nature of multisensory interactions has been the subject of a plethora of studies. From the conceptual viewpoint, we will consider below the three myths of postural regulation that have been rather influential in many experimental studies and mathematical models of human posture control: (1) the posture control system is linear, (2) posture control is determined by reflexes, and (3) posture control is equilibrium control. 


\section{Non-linear Properties of the Posture Control System}

Small movements accompany the maintenance of any posture. Typically, unless human posture is unstable, body segment oscillations do not exceed $1-2^{\circ}$ of joint movements and the CoP oscillations are about $1-2 \mathrm{~cm}$. The fact that postural oscillations are small supports the assumption that the system is linear within a limited range of movements and, therefore, linear computational models and analyses can be applied (Winter et al., 2003; Mergner, 2007; Kiemel et al., 2008; Assländer and Peterka, 2014). While this assumption is valid to some extent and many studies provided very important information about postural strategies and the contribution of different sensory inputs to balance control, one should have in mind that there is also substantial non-linearity in the postural control system, which is often overlooked.

First of all, some non-linearity exists already at the level of muscles, since their resistance to small angular perturbations $\left(\sim 1^{\circ}\right.$, corresponding to about $1 \%$ changes in the muscle fiber length, so-called "short range stiffness," Rack and Westbury, 1974) is much higher than the resistance to larger perturbations. Even though the short range stiffness of active calf muscles might not be sufficient to fully compensate the body sway during quiet standing (Morasso and Schieppati, 1999; Loram et al., 2007), its contribution is definitely essential (Gurfinkel et al., 1995). Thixotropy of skeletal muscles (Gurfinkel et al., 1989a) further contributes to the time-dependent augmentation of muscle stiffness for long-sustained postural movements. Indeed, the short-range stiffness component is smaller during periods of high postural sway. Thus, there is a significant reduction (up to $43 \%$ ) in intrinsic ankle stiffness during conditions of increased baseline sway (Sakanaka et al., 2016), indicating remarkable effects of sway history. Intrafusal fibers of muscle spindles also show thixotropic behavior, implying history-related proprioceptive gain (Proske et al., 1993). In sum, ignoring the non-linear dependence of ankle stiffness on sway size may lead to serious misinterpretation of the results of experiments that use mechanical perturbations or sensory manipulations such as eye closure, movable or unstable support surfaces, sway-referencing, etc. (Loram et al., 2007).

Second, since postural oscillations are small, there are considerable non-linear redistributions of internal displacements of muscle fibers, tendons and soft tissues inside the body. For instance, due to the compliant Achilles tendons, there is paradoxical shortening of soleus and gastrocnemius muscles when the body sways forward and lengthening when the body returns, leaving uncertain the postural role of the numerous calf muscle spindles in the detection of body sway (Loram et al., 2004). Furthermore, the control of equilibrium and internal displacements (of muscle fibers, ligaments and soft tissues) are not restricted to distal joints. For instance, postural disturbances may result from respiratory movements of the thorax and abdomen and should be compensated by movement of the lower limbs and pelvis (Hodges et al., 2002). Moreover, postural stability requires constant activity of axial muscles to stabilize the trunk (and head) and to compensate for movements of the distal parts of the body, if necessary. Finally, the human foot is subjected to considerable deformations during quiet standing due to small CoM displacements and deformations of the soft tissues and the arch of the foot. It is worth stressing that $\sim 0.5 \mathrm{~mm}$ vertical oscillations of the calcaneus (and forefoot) observed during quiet standing in healthy adult individuals (Gurfinkel et al., 1994) produce about $0.5^{\circ}$ of body tilt $(\sim 0.7 \mathrm{~cm} \mathrm{CoP}$ displacements) even in the absence of ankle joint displacements. In young children, these deformations and their influences on posture control are expected to be even larger since a child's foot goes through significant developmental changes in shape and soft tissues of the foot sole (e.g., the presence of a fat pad underneath the foot plantar surface in infants), once the child starts to stand and walk. Moreover, development of the bony structure of the longitudinal arch only starts $\sim 1$ year after birth and continues up to the age of 5 years (Straus, 1926; Maier, 1961). Postural activity of numerous intrinsic foot muscles (that is typically not recorded in postural studies) further contributes to human foot plasticity. There are also large individual differences in foot deformations. These deformations yield large errors in the measured changes of the ankle joint angle, as well as even minute local foot deformations elicit noticeable directional postural responses (Gurfinkel et al., 1994; Wright et al., 2012). However, many postural studies tend to focus on the simple hinge action of the ankle joint (Gatev et al., 1999; Masani et al., 2003; Winter et al., 2003; Mergner, 2007).

The processing of the CoP oscillations imply a certain degree of non-linearity. Upright postural control during quiet standing has often been investigated by quantifying spontaneous postural sway in the displacement, velocity and frequency domains. Nevertheless, the analysis and interpretation of the findings should be carried out carefully since the data processing technique may affect the structure of CoP variability (Rhea et al., 2015). In addition, the similar amplitudes of the CoP oscillations in different animals (Figure 1) raise an important point about their normalization to the body height, body mass and the size of the base of support. Could it reflect an evolutionary adopted sensory threshold for the control of postural sway? Indeed, despite differences in body size, the proprioceptive thresholds (for muscle spindles, joint and load receptors), nerve conduction velocities and the types of muscle fibers are similar for terrestrial mammals, suggesting that a simple size-scaling cannot be applied when comparing sensorimotor control across species (More et al., 2010). Whatever the exact mechanism for comparable CoP oscillations (Figure 1), both mechanical and neural factors are likely to contribute (Gatev et al., 1999; Masani et al., 2003; Winter et al., 2003; Di Giulio et al., 2009; Simoneau and Teasdale, 2015). These considerations are also important for the developmental studies. For example, CoP oscillations are similar or larger (but never smaller) in young children with respect to adult humans notwithstanding over the 2-fold difference in body height (Oba et al., 2015). To some extent, they could be accounted for by the development of postural stability in children. However, we do not know the quantum of CoP oscillations attributable to instability and which proportion may be adjusted due to "unknown" normalization procedure. In other words, we are uncertain about whether and how the CoP amplitude should be 
normalized to the body height for the same animal at different developmental ages.

There are also other non-linear properties of the sensorimotor system, including thresholds (e.g., for vestibular stimulation), time delays of proprioceptive feedback and neuromuscular delays of force production. The nonlinear geometry of musculoskeletal connections (e.g., the dependence of the moment arm of muscles upon joint angle) contributes to non-linear properties of the sensorimotor system, though this type of nonlinearity is more noticeable during relatively large movements or postural perturbations or when changing the postural set. We will not review here numerous postural models and refer to other articles related to nonlinear control strategy, including burst-like muscle activations, observed especially during unstable conditions. It has even been suggested that intermittent open loop control may be an appropriate solution to deal with feedback time delays, motor noise and computational-muscular economy (Loram et al., 2011). The shift of paradigms in future experimental or modeling studies may be related to the development of non-linear approaches (Loram et al., 2011; Nomura et al., 2013; Funato et al., 2016), although complexity of the model may come at the cost of understanding. These limitations force a necessary trade-off between the usage of linear approaches and more complex postural models. Nevertheless, even if we for simplicity apply linear computations (for instance, Kiemel et al., 2008; Assländer and Peterka, 2014), we need to keep in mind considerable non-linearity in the neuromuscular control of posture.

\section{Posture Control as a Summation of Postural Reflexes}

Early postural studies made an emphasis on the reflex nature of postural mechanisms and provided various important examples of static postural reactions (Magnus, 1924; Roberts, 1978). The idea of stretch reflexes, sensory (proprioceptive, visual and vestibular) feedback and its impairment in various forms of pathology of the spinal cord, brainstem and cerebellum, in conjunction with the later developed concept of servoregulation, has been influential in the assessment and modeling of human posture control.

On the other hand, it has been realized that the notion of postural reflexes is rather limited to account for the actual complexity of posture control, which includes anticipatory or feedforward adjustments, context-dependent sensorimotor (or "reflex") modulations, postural body scheme, and integration of posture and movements (Massion, 1994). A noteworthy illustration of the postural body schema is the modulation of automatic postural reactions (e.g., in response to galvanic vestibular stimulation, muscle vibration, or postural perturbation) according to an illusionary rather than real position of the head or body segments (Gurfinkel, 1994). There are several techniques to artificially induce a dissociation between real and perceived body configuration: by eliciting proprioceptive illusions, by using the phenomenon of "return" of subjective head position to the neutral position after its prolonged turning, or by hypnotic suggestion. All these techniques show similar effects on spatially-oriented postural responses to sensory stimulation. Changes in the gaze direction may also modulate postural responses (Ivanenko et al., 1999), consistent with supraspinal or cognitive influences on posture control, likely because the gaze represents an important reference frame for the internal model of spatial orientation. Thus, the fact that automatic postural reactions are accomplished in accordance with internal representation of body scheme (Popov et al., 1986; Smetanin et al., 1988; Gurfinkel, 1994) indicates that it does not only serve for conscious perception of position but it is also the basis for planning and implementing motor activity. The control of balance during both standing and movements depends on a complex interaction of physiological mechanisms, high level processing of sensory information in accordance with the postural body scheme and on the individual's expectations, goals, cognitive factors and prior experience. The body scheme elements exist already at the level of the spinal cord and contribute to the processing of sensory input and postural responses (Fukson et al., 1980; Windhorst, 1996; Poppele and Bosco, 2003). The notion of body schema has received attention in a large context of contemporary motor control to understand adaptability of reflex modulation, a range of processes such as state estimation, prediction, learning, and to bridge the gap between cognitive and motor functions (Gurfinkel, 1994; Maravita and Iriki, 2004; Windhorst, 2007; Pearson and Gramlich, 2010; Ivanenko et al., 2011; MacPherson and Horak, 2012; Herzfeld and Shadmehr, 2014).

In sum, postural control is no longer considered one system or a given set of equilibrium reflexes but rather a motor skill (Horak and Macpherson, 1995). Many studies are focusing on quantifying the reflex gain of specific neural pathways, such as the Hoffman reflex, local stretch reflexes in individual joints, motor evoked potentials, etc. or applying a specific balance test. They provide knowledge about excitability of these pathways in specific conditions. However, the view that a few pathways or centers in the brain are responsible for posture control is quite limiting in our abilities to assess risks of falling and to improve balance. In addition, high-level cortical involvement increases as postural challenges or demands for reactive control increase (Ouchi et al., 1999; Solopova et al., 2003; Varghese et al., 2015). From the diagnostic and rehabilitation viewpoints, "many systems need to be evaluated to understand what is wrong with a person's balance" (Horak, 2006).

\section{Posture Control and Equilibrium Control}

It is typically stated in many articles on posture control that sensory information from somatosensory, vestibular and visual systems are integrated to provide equilibrium maintenance (Fitzpatrick and McCloskey, 1994; Blouin et al., 2007; Mergner, 2007; Assländer and Peterka, 2014; Chiba et al., 2016). Accordingly, a consistent bulk of research focused on postural equilibrium investigates how sensory inputs are reweighted or how neural strategies change in different situations to control balance and postural reactions to perturbations (Nashner, 1976; Ivanenko et al., 1997; Jeka et al., 2004; Schweigart and Mergner, 2008; Nardone and Schieppati, 2010; Simoneau and Teasdale, 
2015; Balestrucci et al., 2017). However, the system of posture control must deal with the two tasks simultaneously, one sets a distribution of tonic muscle activity ("posture") and the other is assigned to compensate for internal or external perturbations ("equilibrium"). Are these two tasks equivalent?

To start with, the control of movement and maintaining a fixed limb posture following movement (holding the body part at its destination) involve distinct neural circuits in the brain stem, cerebellum, motor cortex, hippocampus, etc. (Shadmehr, 2017). For instance, many neurons in the primary motor cortex that express load-related activity are exclusively involved during either posture only or movement only, i.e., they respond differently to transient and continuous loads applied during posture (Kurtzer et al., 2005; Herter et al., 2009). It was suggested that the necessity of having a "hold circuit" may have arisen from the need to maintain a constant "sensory state," while circuits that are responsible for moving the body part change its sensory state. Since the two tasks (movement and holding still) are inherently interrelated, there is also overlapping and interaction between these circuits. Nevertheless, they differ significantly. Neurophysiological data across different modalities regarding the control of gaze, head movements, arm movement, posture and locomotion indicate that distinct interneurons and motoneurons exhibit bursts of activity during transient movements vs. a sustained level of discharge during posture maintenance (Shadmehr, 2017). Accordingly, a similar concept can be applied to the control of phasic and tonic postural muscle activity. As far as it concerns postural tone, it originates from several supraspinal centers, including the reticular formation, vestibular nuclei, cerebellum, and mesodiencephalic nuclei (Hess, 1954). These brain regions can exhibit sustained long-lasting activity providing a prolonged excitation and inhibition of executive motor systems. In addition, there are also specialized pathways to the spinal cord (Kuypers, 1964; Szokol and Perreault, 2009; Deliagina et al., 2014) and specialized activation of the trunk musculature during various postural and motor tasks (Urquhart et al., 2005; Falgairolle et al., 2006, 2013; Tsao et al., 2011; Beliez et al., 2015). For instance, descending pathways to the axial musculature (that links all parts of the body together and provides axial muscle tone and trunk stabilization) via somatic descending brain stem and monoaminergic pathways are distinct from the descending tracts to limb motoneurons (Kuypers, 1964; Szokol et al., 2008; Sivertsen et al., 2014).

Slow and fast processes in the central nervous system are also often linked to the control of muscle tone and phasic muscle activity. For instance, various postural aftereffects are associated with slow changes in the tonic muscle activity (Gurfinkel et al., 1995; Kluzik et al., 2005; Bove et al., 2009; Wright, 2011). In some conditions, posture-related and equilibrium-related control can be differentiated with regard to slow and fast components of CoP displacements, respectively. For instance, participants with occluded vision undergoing super slow $\left(<0.1^{\circ} / \mathrm{s}\right)$ tilts of the supporting platform, subthreshold for most vestibular and proprioceptive phasic reactions, display very large compensatory phase shifts and delays (tens of seconds). It is worth noting, though, that large slow body movements are superimposed with small irregular oscillations reflecting an ongoing equilibrium control (Gurfinkel et al., 1995). Thus, besides operative control assigned to compensate deviations from a reference position, the system of postural control includes at least one additional level, which elaborates this postural "set" taking into account the energy cost of standing, position of body segments, muscular torques and demands for stability and security. From a functional point of view, this may solve the old posture-movement paradox introduced by a famous German scientist, Erich von Holst (19081962): how we can move from one posture to another without triggering resistance from posture-stabilizing mechanisms. If one considers posture and equilibrium to be mediated by distinct neural circuits, posture-stabilizing mechanisms may be responsible for the control of equilibrium relative to the superiorly determined postural set.

The basis of habitual sitting or standing human posture is postural tone of skeletal muscles. Phasic activity is often voluntary (though it may be automatic as well) while tonic involuntary activity is less known and much less studied. There are methodological difficulties since the activity in many (e.g., trunk) muscles is rather small. Under narcosis, muscle tone disappears while tonic activity can be observed during sleeping, since there are some active phases accompanied by muscle tonic contractions (Harris, 2005; Peever, 2011; Huon and Guilleminault, 2017). Among important examples of long-lasting involuntary activity are the tonic vibration reflex (Eklund and Hagbarth, 1966) and involuntary postcontraction muscle activity (Salmon, 1914; Kohnstamm, 1915) that have been suggested to represent an amplification of neuromotor processes normally involved in automatic posture maintenance and tonic spinal activity (De Havas et al., 2017; Ivanenko et al., 2017).

An important issue is an evaluation and definition of muscle tone (Gurfinkel et al., 2011), which is traditionally linked to the activity level of muscle. In clinical practice, changes in tonus are typically measured, not tonus per se, by the extent of the muscle resistance to stretch. However, muscle length changes may also evoke involuntary shortening reactions (compliant posture behavior) or elicit postural adjustments of other "remote" muscles not being primarily stretched (Andrews et al., 1972; Gurfinkel et al., 1989b). A dynamic "postural frame," that is inherently incorporated in posture and movement coordination, may account for the resistive or compliant behavior of the body (Cacciatore et al., 2014). In this respect, Bernstein's (1940) interpretation of muscle tone seems more functional, as the degree of readiness for movement related to movement as a state is related to an action, or as a precondition is related to an effect. Changes in muscle tone affect movements. The remarkable findings of the British neurologist Martin (1967) provide excellent examples of how disturbances to postural tone in humans affect the ability to perform movements. For instance, the loss of normal posture of the head and trunk can be observed in patients with eyes closure while inability to hold the body up may result in a gradually flexed posture during walking. Furthermore, disturbances of trunk posture, its dynamics and variability during walking may differ for idiopathic and parkinsonian camptocormia, suggesting the involvement of different underlying physiopathological mechanisms (de Sèze et al., 2015). In addition, trunk postural adjustments may 
also depend on walking conditions, for instance, forward vs. backward walking (Ivanenko et al., 2013). These disturbances are related primarily to automatic rather than voluntary control of posture (Wright et al., 2007; Ivanenko et al., 2013). The level of tonic muscle activity substantially influences postural orientation (Martin, 1967; Kluzik et al., 2005; Wright, 2011) and is inherently incorporated in gait control (Mori, 1989).

In summary, the central nervous system is able to combine mobility with stability and the nature of interactions between posture and movement is a long-standing problem in movement neuroscience. The latter aspect was best described by Sherrington (1906) more than a century ago-" "posture follows movement like a shadow." It even anticipates movement. Tonic muscle activity and posture control require specialized neural circuitry. An appropriate postural tone is an integral part of any movement and disturbances to muscle tone may in turn affect movement performance. In order to understand the control of posture and movements, we need to know better how postural tone

\section{REFERENCES}

Andrews, C. J., Burke, D., and Lance, J. W. (1972). The response to muscle stretch and shortening in parkinsonian rigidity. Brain 95, 795-812. doi: 10.1093/brain/95.4.795

Assländer, L., and Peterka, R. J. (2014). Sensory reweighting dynamics in human postural control. J. Neurophysiol. 111, 1852-1864. doi: 10.1152/jn.00669.2013

Balestrucci, P., Daprati, E., Lacquaniti, F., and Maffei, V. (2017). Effects of visual motion consistent or inconsistent with gravity on postural sway. Exp. Brain Res. 235, 1999-2010. doi: 10.1007/s00221-017-4942-3

Beliez, L., Barrière, G., Bertrand, S. S., and Cazalets, J. R. (2015). Origin of thoracic spinal network activity during locomotor-like activity in the neonatal rat. $J$. Neurosci. 35, 6117-6130. doi: 10.1523/JNEUROSCI.4145-14.2015

Bernstein, N. A. (1940). "Studies of the Biodynamics of Walking, Running and Jumping. Moscow, Researches of the Central Scientific Institute of Physical Culture. (In Russian). English translation," in Human Motor Actions. Bernstein Reassessed, ed H. T. A. Whiting (1984) (Amsterdam: North-Holland), 171-222.

Blouin, J., Teasdale, N., and Mouchnino, L. (2007). Vestibular signal processing in a subject with somatosensory deafferentation: the case of sitting posture. BMC Neurol. 7:25. doi: 10.1186/1471-2377-7-25

Bove, M., Fenoggio, C., Tacchino, A., Pelosin, E., and Schieppati, M. (2009). Interaction between vision and neck proprioception in the control of stance. Neuroscience 164, 1601-1608. doi: 10.1016/j.neuroscience.2009.09.053

Brookhart, J. M., Parmeggiani, P. L., Petersen, W. A., and Stone, S. A. (1965). Postural stability in the dog. Am. J. Physiol. 208, 1047-1057. doi: 10.1152/ajplegacy.1965.208.6.1047

Cacciatore, T. W., Mian, O. S., Peters, A., and Day, B. L. (2014). Neuromechanical interference of posture on movement: evidence from Alexander technique teachers rising from a chair. J. Neurophysiol. 112, 719-729. doi: 10.1152/jn.00617.2013

Caneiro, J. P., O’Sullivan, P., Burnett, A., Barach, A., O’Neil, D., Tveit, O., et al. (2010). The influence of different sitting postures on head/neck posture and muscle activity. Man. Ther. 15, 54-60. doi: 10.1016/j.math.2009.06.002

Chiba, R., Takakusaki, K., Ota, J., Yozu, A., and Haga, N. (2016). Human upright posture control models based on multisensory inputs; in fast and slow dynamics. Neurosci. Res. 104, 96-104. doi: 10.1016/j.neures.2015.12.002

Chu, M., Gregorio, C. C., and Pappas, C. T. (2016). Nebulin, a multi-functional giant. J. Exp. Biol. 219, 146-152. doi: 10.1242/jeb.126383

Clayton, H. M., and Nauwelaerts, S. (2014). Effect of blindfolding on centre of pressure variables in healthy horses during quiet standing. Vet. J. 199, 365-369. doi: $10.1016 /$ j.tvjl.2013.12.018

Colombini, B., Nocella, M., and Bagni, M. A. (2016). Non-crossbridge stiffness in active muscle fibres. J. Exp. Biol. 219, 153-160. doi: 10.1242/jeb.124370 is generated and maintained, including its neuromuscular underpinnings.

\section{AUTHOR CONTRIBUTIONS}

All authors listed have made a substantial, direct and intellectual contribution to the work, and approved it for publication.

\section{FUNDING}

This work was supported by the Italian Ministry of Health (IRCCS Ricerca corrente) and Horizon 2020 Robotics Program (ICT-23-2014 under Grant Agreement 644727-CogIMon).

\section{ACKNOWLEDGMENTS}

The authors thank Dr. Gianfranco Bosco for his helpful comments on the early version of the manuscript.

Dayanidhi, S., Kutch, J. J., and Valero-Cuevas, F. J. (2013). Decrease in muscle contraction time complements neural maturation in the development of dynamic manipulation. J. Neurosci. 33, 15050-15055. doi: 10.1523/JNEUROSCI.1968-13.2013

De Havas, J., Gomi, H., and Haggard, P. (2017). Experimental investigations of control principles of involuntary movement: a comprehensive review of the Kohnstamm phenomenon. Exp. Brain Res. 235, 1953-1997. doi: 10.1007/s00221-017-4950-3

Deliagina, T. G., Beloozerova, I. N., Orlovsky, G. N., and Zelenin, P. V. (2014). Contribution of supraspinal systems to generation of automatic postural responses. Front. Integr. Neurosci. 8:76. doi: 10.3389/fnint.2014.00076

de Sèze, M. P., Guillaud, E., Slugacz, L., and Cazalets, J. R. (2015). An examination of camptocormia assessment by dynamic quantification of sagittal posture. J. Rehabil. Med. 47, 72-79. doi: 10.2340/16501977-1888

Di Giulio, I., Maganaris, C. N., Baltzopoulos, V., and Loram, I. D. (2009). The proprioceptive and agonist roles of gastrocnemius, soleus and tibialis anterior muscles in maintaining human upright posture. J. Physiol. (Lond.) 587, 2399-2416. doi: 10.1113/jphysiol.2009.168690

Eklund, G., and Hagbarth, K. E. (1966). Normal variability of tonic vibration reflexes in man. Exp. Neurol. 16, 80-92. doi: 10.1016/0014-4886(66) 90088-4

Falgairolle, M., Ceccato, J. C., Seze, M., de, Herbin, M., and Cazalets, J. R. (2013). Metachronal propagation of motor activity. Front. Biosci. (Landmark Ed) 18, 820-837. doi: $10.2741 / 4146$

Falgairolle, M., de Seze, M., Juvin, L., Morin, D., and Cazalets, J. R. (2006). Coordinated network functioning in the spinal cord: An evolutionary perspective. J Physiol. Paris 100, 304-316. doi: 10.1016/j.jphysparis.2007. 05.003

Fitzpatrick, R., and McCloskey, D. I. (1994). Proprioceptive, visual and vestibular thresholds for the perception of sway during standing in humans. J. Physiol. (Lond.) 478 (Pt 1), 173-186. doi: 10.1113/jphysiol.1994.sp020240

Fukson, O. I., Berkinblit, M. B., and Feldman, A. G. (1980). The spinal frog takes into account the scheme of its body during the wiping reflex. Science 209, 1261-1263. doi: 10.1126/science.7403886

Funato, T., Aoi, S., Tomita, N., and Tsuchiya, K. (2016). Smooth enlargement of human standing sway by instability due to weak reaction floor and noise. $R$. Soc. Open Sci. 3:150570. doi: 10.1098/rsos.150570

Galen, A., (1549). De Motu Musculorum. Leiden: Rouillum.

Gatev, P., Thomas, S., Kepple, T., and Hallett, M. (1999). Feedforward ankle strategy of balance during quiet stance in adults. J. Physiol. (Lond.) 514 (Pt 3), 915-928. doi: 10.1111/j.1469-7793.1999.915ad.x

Gautel, M., and Djinović-Carugo, K. (2016). The sarcomeric cytoskeleton: from molecules to motion. J. Exp. Biol. 219, 135-145. doi: 10.1242/jeb.124941 
Gurfinkel, V., Cacciatore, T. W., Cordo, P., Horak, F., Nutt, J., and Skoss, R. (2006). Postural muscle tone in the body axis of healthy humans. J. Neurophysiol. 96, 2678-2687. doi: 10.1152/jn.00406.2006

Gurfinkel, V. S. (1994). "The mechanisms of postural regulation in man," in Physiology and general biology reviews, eds T. M. Turpaev and N. K. Koltsov (Harwood, ND: Academic Publishers GmbH), 59-87.

Gurfinkel, V. S., Cacciatore, T. W., Cordo, P. J., and Horak, F. B. (2011). Method to measure tone of axial and proximal muscle. J. Vis. Exp. 3677. doi: 10.3791/3677

Gurfinkel, V. S., Ivanenko, Y. P., and Levik, Y. S. (1989a). Dissipative processes in human passive skeletal muscle. Biofizika 34, 499-503.

Gurfinkel, V. S., Ivanenko, Y. P., and Levik, Y. S. (1994). The contribution of foot deformation to the changes of muscular length and angle in the ankle joint during standing in man. Physiol. Res. 43, 371-377.

Gurfinkel, V. S., Ivanenko, Y. P., Levik, Y. S., and Babakova, I. A. (1995). Kinesthetic reference for human orthograde posture. Neuroscience 68, 229-243. doi: 10.1016/0306-4522(95)00136-7

Gurfinkel', V. S., Levik, Y. S., and Lebedev, M. A. (1989b). Immediate and remote postactivation effects in the human motor system. Neurophysiology 21, $343-351$.

Harris, C. D. (2005). Neurophysiology of sleep and wakefulness. Respir. Care Clin. N. Am. 11, 567-586. doi: 10.1016/j.rcc.2005.08.001

Herter, T. M., Korbel, T., and Scott, S. H. (2009). Comparison of neural responses in primary motor cortex to transient and continuous loads during posture. $J$. Neurophysiol. 101, 150-163. doi: 10.1152/jn.90230.2008

Herzfeld, D. J., and Shadmehr, R. (2014). Cerebellum estimates the sensory state of the body. Trends Cogn. Sci. (Regul. Ed.) 18, 66-67. doi: $10.1016 /$ j.tics.2013.10.015

Hess, W. R. (1954). Diencephalon. Anatomy and Extrapyramidal Functions. New York, NY: Grune and Stratton.

Hodges, P. W., Gurfinkel, V. S., Brumagne, S., Smith, T. C., and Cordo, P. C. (2002). Coexistence of stability and mobility in postural control: evidence from postural compensation for respiration. Exp. Brain Res. 144, 293-302. doi: $10.1007 / \mathrm{s} 00221-002-1040-\mathrm{x}$

Hoppeler, H. (2016). Molecular networks in skeletal muscle plasticity. J. Exp. Biol. 219, 205-213. doi: 10.1242/jeb.128207

Horak, F. B. (2006). Postural orientation and equilibrium: what do we need to know about neural control of balance to prevent falls? Age Ageing 35 (Suppl. 2), ii7-ii11. doi: 10.1093/ageing/afl077

Horak, F. B., and Macpherson, J. M. (1995). "Postural Orientation and Equilibrium," in Integration of motor, circulatory, respiratory and metabolic control during exercise. Section 12, eds J. Shepard, and L. Rowell (New York, NY: Handbook of Physiology; Oxford University Press), 1-39.

Huon, L. A., and Guilleminault, C. (2017). A Succinct History of Sleep Medicine. Adv. Otorhinolaryngol. 80, 1-6. doi: 10.1159/000470486

Huxley, A. F., and Niedergerke, R. (1954). Structural changes in muscle during contraction; interference microscopy of living muscle fibres. Nature 173, 971-973. doi: 10.1038/173971a0

Huxley, H., and Hanson, J. (1954). Changes in the cross-striations of muscle during contraction and stretch and their structural interpretation. Nature 173, 973-976. doi: 10.1038/173973a0

Ivanenko, Y. P., Dominici, N., Daprati, E., Nico, D., Cappellini, G., and Lacquaniti, F. (2011). Locomotor body scheme. Hum. Mov. Sci. 30, 341-351. doi: 10.1016/j.humov.2010.04.001

Ivanenko, Y. P., Grasso, R., and Lacquaniti, F. (1999). Effect of gaze on postural responses to neck proprioceptive and vestibular stimulation in humans. J. Physiol. (Lond.) 519 (Pt 1), 301-314. doi: 10.1111/j.1469-7793.1999. 03010.x

Ivanenko, Y. P., Gurfinkel, V. S., Selionov, V. A., Solopova, I. A., SylosLabini, F., Guertin, P. A., et al. (2017). Tonic and rhythmic spinal activity underlying locomotion. Curr. Pharm. Des. 23, 1753-1763. doi: 10.2174/1381612823666170125152246

Ivanenko, Y. P., Levik, Y. S., Talis, V. L., and Gurfinkel, V. S. (1997). Human equilibrium on unstable support: the importance of feet-support interaction. Neurosci. Lett. 235, 109-112. doi: 10.1016/S0304-3940(97) 00721-0

Ivanenko, Y. P., Wright, W. G., St George, R. J., and Gurfinkel, V. S. (2013). Trunk orientation, stability, and quadrupedalism. Front. Neurol. 4:20. doi: 10.3389/fneur.2013.00020
Jankovic, J. (2003). "Pathophysiology and clinical assessment of parkinsonian symptoms and signs," in Handbook of Parkinson's Disease, 3rd Edn., eds R. Pahwa, K. E. Lyons, and W. C. Koller III (NewYork, NY: Marcel Dekker), 71-107.

Jeka, J., Kiemel, T., Creath, R., Horak, F., and Peterka, R. (2004). Controlling human upright posture: velocity information is more accurate than position or acceleration. J. Neurophysiol. 92, 2368-2379. doi: 10.1152/jn. 00983.2003

Kiemel, T., Elahi, A. J., and Jeka, J. J. (2008). Identification of the plant for upright stance in humans: multiple movement patterns from a single neural strategy. J. Neurophysiol. 100, 3394-3406. doi: 10.1152/jn.01272.2007

Kluzik, J., Horak, F. B., and Peterka, R. J. (2005). Differences in preferred reference frames for postural orientation shown by after-effects of stance on an inclined surface. Exp. Brain Res. 162, 474-489. doi: 10.1007/s00221-004-2124-6

Knight, K. (2016). Muscle revisited. J. Exp. Biol. 219, 129-133. doi: $10.1242 /$ jeb.136226

Kohnstamm, O. (1915). Demonstration einer katatonieartigen Erscheinung beim Gesunden (Katatonusversuch). Neurol Zentral Bl 34S, 290-291.

Kurtzer, I., Herter, T. M., and Scott, S. H. (2005). Random change in cortical load representation suggests distinct control of posture and movement. Nat. Neurosci. 8, 498-504. doi: 10.1038/nn1420

Kuypers, H. G. (1964). The descending pathways to the spinal cord, their anatomy and function. Prog. Brain Res. 11, 178-202. doi: 10.1016/S0079-6123(08)64048-0

Loram, I. D., Gollee, H., Lakie, M., and Gawthrop, P. J. (2011). Human control of an inverted pendulum: is continuous control necessary? Is intermittent control effective? Is intermittent control physiological? J. Physiol. (Lond.) 589, 307-324. doi: 10.1113/jphysiol.2010.194712

Loram, I. D., Maganaris, C. N., and Lakie, M. (2004). Paradoxical muscle movement in human standing. J. Physiol. (Lond.) 556, 683-689. doi: 10.1113/jphysiol.2004.062398

Loram, I. D., Maganaris, C. N., and Lakie, M. (2007). The passive, human calf muscles in relation to standing: the non-linear decrease from short range to long range stiffness. J. Physiol. (Lond.) 584, 661-675. doi: 10.1113/jphysiol.2007.140046

MacPherson, J., and Horak, F. B. (2012). "Posture," in Principles of Neural Science. 5 th Edn, Chapter 41, eds E. Kandel, J. Schwartz, T. Jessell, S. Siegelbaum, and A. J. Hudspeth (New York, NY: McGraw-Hill), 935-959.

Magnus, R. (1924). Körperstellung. Berlin, Heidelberg: Springer

Magnus, R., and de Klein, A. (1912). Die abhangigkeit des tonus der extremitaten muskeln von der kopfstellung. Pflug. Arch. Gesamte Physiol. Menschen Tiere 145, 455-548. doi: 10.1007/BF01681127

Maier, E. (1961). [Longitudinal measurement research on the maturation of the child's foot]. Monatsschr. Kinderheilkd. 109, 222-226.

Maravita, A., and Iriki, A. (2004). Tools for the body (schema). Trends Cogn. Sci. (Regul. Ed.) 8, 79-86. doi: 10.1016/j.tics.2003.12.008

Martin, J. P. (1967). The Basal Ganglia and Posture. London: Pitman Medical Publishing Co. LTD.

Masani, K., Popovic, M. R., Nakazawa, K., Kouzaki, M., and Nozaki, D. (2003). Importance of body sway velocity information in controlling ankle extensor activities during quiet stance. J. Neurophysiol. 90, 3774-3782. doi: 10.1152/jn.00730.2002

Massion, J. (1994). Postural control system. Curr. Opin. Neurobiol. 4, 877-887. doi: 10.1016/0959-4388(94)90137-6

Mergner, T. (2007). Modeling sensorimotor control of human upright stance. Prog. Brain Res. 165, 283-297. doi: 10.1016/S0079-6123(06)65018-8

Morasso, P. G., and Schieppati, M. (1999). Can muscle stiffness alone stabilize upright standing? J. Neurophysiol. 82, 1622-1626. doi: 10.1152/jn.1999.82.3.1622

More, H. L., Hutchinson, J. R., Collins, D. F., Weber, D. J., Aung, S. K., and Donelan, J. M. (2010). Scaling of sensorimotor control in terrestrial mammals. Proc. Biol. Sci. 277, 3563-3568. doi: 10.1098/rspb.2010.0898

Mori, S. (1989). Contribution of postural muscle tone to full expression of posture and locomotor movements: multi-faceted analyses of its setting brainstem-spinal cord mechanisms in the cat. Jpn. J. Physiol. 39, 785-809. doi: 10.2170/jjphysiol.39.785

Nardone, A., and Schieppati, M. (2010). The role of instrumental assessment of balance in clinical decision making. Eur. J. Phys. Rehabil. Med. 46, 221-237. 
Nashner, L. M. (1976). Adapting reflexes controlling the human posture. Exp. Brain Res. 26, 59-72. doi: 10.1007/BF00235249

Nishikawa, K. (2016). Eccentric contraction: unraveling mechanisms of force enhancement and energy conservation. J. Exp. Biol. 219, 189-196. doi: $10.1242 /$ jeb. 124057

Nomura, T., Oshikawa, S., Suzuki, Y., Kiyono, K., and Morasso, P. (2013). Modeling human postural sway using an intermittent control and hemodynamic perturbations. Math. Biosci. 245, 86-95. doi: $10.1016 /$ j.mbs.2013.02.002

Oba, N., Sasagawa, S., Yamamoto, A., and Nakazawa, K. (2015). Difference in Postural control during quiet standing between young children and adults: assessment with center of mass acceleration. PLOS ONE 10:e0140235. doi: 10.1371/journal.pone.0140235

Ouchi, Y., Okada, H., Yoshikawa, E., Nobezawa, S., and Futatsubashi, M. (1999). Brain activation during maintenance of standing postures in humans. Brain 122 (Pt 2), 329-338. doi: 10.1093/brain/122.2.329

Pearson, K., and Gramlich, R. (2010). Updating neural representations of objects during walking. Ann. N.Y. Acad. Sci. 1198, 1-9. doi: 10.1111/j.1749-6632.2009.05422.x

Peever, J. (2011). Control of motoneuron function and muscle tone during REM sleep, REM sleep behavior disorder and cataplexy/narcolepsy. Arch. Ital. Biol. 149, 454-466. doi: 10.4449/aib.v149i4.1257

Popov, K. E., Smetanin, B. N., Gurfinkel', V. S., Kudinova, M. P., and Shlykov, V. I. $(1986)$. Spatial perception and vestibulomotor reactions in man. Neirofiziologiia $18,779-787$.

Poppele, R., and Bosco, G. (2003). Sophisticated spinal contributions to motor control. Trends Neurosci. 26, 269-276. doi: 10.1016/S0166-2236(03)00073-0

Proske, U., Morgan, D. L., and Gregory, J. E. (1993). Thixotropy in skeletal muscle and in muscle spindles: a review. Prog Neurobiol. 41, 705-721. doi: 10.1016/0301-0082(93)90032-N

Rack, P. M., and Westbury, D. R. (1974). The short range stiffness of active mammalian muscle and its effect on mechanical properties. J. Physiol. (Lond.) 240, 331-350. doi: 10.1113/jphysiol.1974.sp010613

Rademaker, G. G. J. (1931). Das Stehen. Berlin; Heidelberg: Springer

Rhea, C. K., Kiefer, A. W., Wright, W. G., Raisbeck, L. D., and Haran, F. J. (2015). Interpretation of postural control may change due to data processing techniques. Gait Posture 41, 731-735. doi: 10.1016/j.gaitpost.2015.01.008

Roberts, T. D. M. (1978). Neurophysiology of Postural Mechanisms. 2nd Edn. London, Boston: Butterworth-Heinemann Ltd.

Sakanaka, T. E., Lakie, M., and Reynolds, R. F. (2016). Sway-dependent changes in standing ankle stiffness caused by muscle thixotropy. J. Physiol. (Lond.) 594, 781-793. doi: 10.1113/JP271137

Salmon, A. (1914). Nuove osservazioni sui movimenti automatici che si compiono dopo gli sforzi muscolari e del Ioro valore in neuropatologia. Atti Della Accademia Medico Fisica Fiorentina 78-91.

Sato, Y., Funato, T., Yanagihara, D., Sato, Y., Aoi, S., Fujiki, S., et al. (2015). Measuring body sway of bipedally standing rat and quantitative evaluation of its postural control. Conf. Proc. IEEE Eng. Med. Biol. Soc. 2015, 5311-5314. doi: 10.1109/EMBC.2015.7319590

Schweigart, G., and Mergner, T. (2008). Human stance control beyond steady state response and inverted pendulum simplification. Exp. Brain Res. 185, 635-653. doi: 10.1007/s00221-007-1189-4

Shadmehr, R. (2017). Distinct neural circuits for control of movement vs. holding still. J. Neurophysiol. 117, 1431-1460. doi: 10.1152/jn.00840.2016

Sherrington, C. (1906). The Integrative Action of the Nervous System. New York, NY: Charles Scribner's Sons.

Sherrington, C. S. (1915). Postural activity of muscle and nerve. Brain 38, 191-234. doi: 10.1093/brain/38.3.191

Simoneau, M., and Teasdale, N. (2015). Balance control impairment in obese individuals is caused by larger balance motor commands variability. Gait Posture 41, 203-208. doi: 10.1016/j.gaitpost.2014.10.008
Sivertsen, M. S., Glover, J. C., and Perreault, M. C. (2014). Organization of pontine reticulospinal inputs to motoneurons controlling axial and limb muscles in the neonatal mouse. J. Neurophysiol. 112, 1628-1643. doi: 10.1152/jn.008 20.2013

Smetanin, B. N., Popov, K. E., Gurfinkel', V. S., and Shlykov, V. I. (1988). Effect of real and illusory movements on the human vestibulomotor reaction. Neirofiziologiia 20, 250-255.

Solopova, I. A., Kazennikov, O. V., Deniskina, N. B., Levik, Y. S., and Ivanenko, Y. P. (2003). Postural instability enhances motor responses to transcranial magnetic stimulation in humans. Neurosci. Lett. 337, 25-28. doi: 10.1016/S0304-3940(02)01297-1

Straus, W. L. (1926). The development of the human foot and its phylogenetic significance. Am. J. Phys. Anthropol. 9, 427-438. doi: 10.1002/ajpa.1330 090416

Szokol, K., Glover, J. C., and Perreault, M. C. (2008). Differential origin of reticulospinal drive to motoneurons innervating trunk and hindlimb muscles in the mouse revealed by optical recording. J. Physiol. (Lond.) 586, 5259-5276. doi: 10.1113/jphysiol.2008. 158105

Szokol, K., and Perreault, M. C. (2009). Imaging synaptically mediated responses produced by brainstem inputs onto identified spinal neurons in the neonatal mouse. J. Neurosci. Methods 180, 1-8. doi: 10.1016/j.jneumeth.2009.01.018

Tsao, H., Danneels, L., and Hodges, P. W. (2011). Individual fascicles of the paraspinal muscles are activated by discrete cortical networks in humans. Clin. Neurophysiol. 122, 1580-1587. doi: 10.1016/j.clinph.2011.01.048

Urquhart, D. M., Hodges, P. W., and Story, I. H. (2005). Postural activity of the abdominal muscles varies between regions of these muscles and between body positions. Gait Posture 22, 295-301. doi: 10.1016/j.gaitpost.2004. 09.012

Varghese, J. P., Beyer, K. B., Williams, L., Miyasike-daSilva, V., and McIlroy, W. E. (2015). Standing still: is there a role for the cortex? Neurosci. Lett. 590, 18-23. doi: 10.1016/j.neulet.2015.01.055

Windhorst, U. (1996). The spinal cord and its brain: representations and models. To what extent do forebrain mechanisms appear at brainstem spinal cord levels? Prog. Neurobiol. 49, 381-414. doi: 10.1016/0301-0082(96)00022-6

Windhorst, U. (2007). Muscle proprioceptive feedback and spinal networks. Brain Res. Bull. 73, 155-202. doi: 10.1016/j.brainresbull.2007.03.010

Winter, D. A., Patla, A. E., Ishac, M., and Gage, W. H. (2003). Motor mechanisms of balance during quiet standing. J. Electromyogr. Kinesiol. 13, 49-56. doi: 10.1016/S1050-6411(02)00085-8

Wright, W. G. (2011). Tonic postural lean after-effects influenced by support surface stability and dynamics. Hum. Mov. Sci. 30, 238-248. doi: 10.1016/j.humov.2010.05.006

Wright, W. G., Gurfinkel, V. S., Nutt, J., Horak, F. B., and Cordo, P. J. (2007). Axial hypertonicity in Parkinson's disease: direct measurements of trunk and hip torque. Exp. Neurol. 208, 38-46. doi: 10.1016/j.expneurol.2007. 07.002

Wright, W. G., Ivanenko, Y. P., and Gurfinkel, V. S. (2012). Foot anatomy specialization for postural sensation and control. J. Neurophysiol. 107, 1513-1521. doi: 10.1152/jn.00256.2011

Conflict of Interest Statement: The authors declare that the research was conducted in the absence of any commercial or financial relationships that could be construed as a potential conflict of interest.

Copyright (C) 2018 Ivanenko and Gurfinkel. This is an open-access article distributed under the terms of the Creative Commons Attribution License (CC BY). The use, distribution or reproduction in other forums is permitted, provided the original author(s) and the copyright owner are credited and that the original publication in this journal is cited, in accordance with accepted academic practice. No use, distribution or reproduction is permitted which does not comply with these terms. 